\title{
A Study of English Inversions Within the Framework of Figure-Ground Theory
}

\author{
Yi Jiang, Jing Chen* \\ School of Foreign languages, Hangzhou normal University \\ *Corresponding author. Email: jeanchan78@163.com

\begin{abstract}
English inversion is an very important and difficult point in students' English learning. However, the traditional teaching approach is not an effective way to help students master English inversions. From the perspective of cognition, this thesis studies English inversions within the framework of Figure-Ground Theory and applies Figure-Ground Theory in the teaching of English inversions.
\end{abstract}

Keywords: English inversions, Figure-Ground Theory, The teaching of English inversions.

\section{INTRODUCTION}

As a kind of sentence structure, inversion is one of the most important grammatical points in English teaching. Traditional teaching approach mainly focuses on the structure of English inversions, but fails to explain the fundamental principle, so many students fail to understand how such sentence patterns form. Therefore, English inversions teaching and learning are still a big problem for teachers and students.

With the help of Figure-Ground Theory, this study expounds the whole process of inversion's cognitive generation in detail and apply this theory in English inversions teaching, providing new perspectives for learning and understanding English inversions.

\section{ENGLISH INVERSION}

\subsection{Definition of English Inversion}

In recent years, some scholars have begun to use the theory of cognitive linguistics to study English inversions. This study adopts Zhang Keding's (2001) definition of English inversions within the framework of Figure-Ground Theory. Zhang Keding puts forward that English inversion is a marked clause that deviates from people's cognitive law. In terms of cognition, the speakers (writers) tend to change unmarked clauses of Subject (Figure) - Predicator - Complement (Ground) into marked clauses of Complement (Ground) Predicative - Subject (Figure) to realize their communicative intention. This process can place the hearers' or readers' attention on the ground firstly to construct a cognitive reference point, and eventually the figure stands out, which is focused by the hearers or readers.

\subsection{Teaching Applications of English Inversions}

In English inversions teaching, teachers mainly use traditional teaching approach to explain the form, structure and features of English inversions, and let students do lots of exercises to master English inversions. Through this approach, students just learn English inversions mechanically. Therefore, this thesis explains English inversions by using the Figure-Ground Theory. The aim is to help students have a deeper understanding of English inversions.

\section{FIGURE-GROUND THEORY}

Figure-Ground Theory is a theory based on the principle of salience. Based on the basic idea of Figure-Ground Theory, this paper discusses the realization of the cognitive structure of "Figure-Ground Theory" in English inversions from the prominence view and the attention view.

\subsection{Introduction of Figure-Ground Theory}

Figure-Ground Theory is a kind of cognitive perspective. Rubin (1921) was the first psychologist to introduce a phenomenon called figure/ground segregation into psychology and later integrated into a more comprehensive perceptual organizational 
framework by Gestalt psychologists. Figure 1below is a case in point.

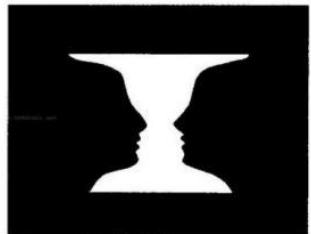

Figure 1 The face/vase illusion

One may notice two possibilities of perceiving the picture (as two faces or as a vase). If one takes the white part as the ground, the black part will be easily seen as two faces; if one takes the black part as the ground, the white part will be easily seen as a vase. Later, Ungerer \& Schmid (2001: 157) claim that "the figure has form or shape whereas the ground is formless and the shared contour seems to belong to the figure." For example, the figure (book) in Example (1) is perceived as being more prominent than the ground (table) in Example (1).

(1) A book is on the table.

In summary, cognitive linguists study Figure-Ground Theory in a cognitive approach. They argue that the figure is more prominent than the ground.

\subsection{Cognitive Approach of Figure-Ground Theory}

According to Ungerer \& Schmid (2001: 200), prominence is one of the three principles guiding cognitive processing; the other two, which in a way are dovetailed with it, are specificity and perspective.

The principles of prominence and specificity are from the prominence view, in that "when we look at an object in our environment, we single it out as a perceptually prominent figure standing out from the ground" (Ungerer \& Schmid ibid: 163). What's more, the principle of perspective is from the attention view, because "the basis for perspective is mainly by the cognitive ability of directing one's attention" (Ungerer \& Schmid 2001: 209).

\section{REALIZATION OF FIGURE-GROUND THEORY IN ENGLISH INVERSION}

As a cognitive model, "Figure-Ground" can effectively explain the formation of English inversion and its function. In essence, English inversion is the realization of this cognitive model in language. Based on Figure-Ground Theory, English inversion is such a mechanism that the movement of subject and complement can change unmarked clauses of Figure (Subject) - Predicator - Ground (Complement) into marked clauses of Ground (Complement) - Predicative - Figure (Subject). By acquiring such mechanism, students can have a better understanding of English inversions.

\subsection{Analysis of English Inversion Using the Principle of Prominence}

The prominence view provides the explanation of how the information in a clause is selected and arranged.

(2) The beggar made no answer. He grasped his staff with a firmer grip and gazed across the hall where was the lofty strairway that led to the queen's chambers. Down the stairs (G) came Penelope, stately and beautiful, with her servants and maids around her (F). (Baldwin, 1984: 278)

(3) On one of the islands $(\mathrm{G})$ was a lighthouse (F); and there, all through that stormy night, Grace Darling had listened to the storm. (Baldwin, 1984: 46)

"Penelope, stately and beautiful..." in Example (2) and "lighthouse" in Example (3) are the most interesting and prominent, so the speaker tends to regard them as the figures and through this process, the focus transfer to the end of the sentence, achieving the prominence. And in the prominence view, the hearers or readers pay more attention to the ground firstly, however, when the figure appears, it will draw more attention of the hearers or readers in that they not merely know the fact of the existence of the figure, but also make efforts to find out the figure. What's more, the hearers or readers pay more attention to the figure than ground because the figure is what the speakers or writers subjectively make the hearers or readers know and focus on, and it is what the hearers or readers want to know.

Thus, through teachers' explanation of English inversions using the principle of prominence, students can figure out how the information in a clause is selected and arranged.

\subsection{Analysis of English Inversion Using the Principle of Perspective}

The foundation for perspective is mainly provided by the cognitive ability to direct one's attention. (Ungerer \& Schmid, 2001: 209) What's more, the perspective is also assumed to cover what Langacker (2004) calls the psychological aspects of speech acts, which encompass the basics of pragmatic description such as Grice's Cooperative Principle. It can be explained by Example (4):

(4) a. John (F) is on my right $(\mathrm{G})$.

b. On my right $(\mathrm{G})$ is John $(\mathrm{F})$.

From this example, it can be seen that the subject in (4a) is still the subject in (4b), the complement in (4a) is still the complement in (4b): the figure in (4b) is still the figure in (4b), and the ground in (4a) is still the ground 
in (4b): the predicator and predicative are not changed, but the figure in (4a) has evolved into the figure in (4b). The reason is that after this dynamic process from (4a) to (4b), (4b) as a variant brings the subjective intention of the speaker, which causes the listener to pay more attention to the marked focus information. We can imagine such a scenario: Mike and Mary are very good friends, and Mike didn't know John just on the right of Mary. Mike said to Mary: "John's performance was wonderful!" Mary might say (4a), i.e. John was on my right. It is just Mary' general approval or simple response to Mike. When Mike said to Mary: “John's performance was so bad!" Mary might use (4b) to answer Mike. Obviously, Mary here not only stated a fact but also expressed a subjective intention to remind Mike of not speaking ill of John. And Mike could understand this subjective intention through this marked clause.

Thus, through teachers' explanation of English inversions using the principle of perspective, students can understand the subjective intention in inversions.

\subsection{Analysis of English Inversion Using the Principle of Specificity}

Specificity is often used to describe objects' feature which is singled out as a perceptually prominent and can be explained from the prominence view. For example:

(5) Lonely (G) was Hester's situation (F), and without a friend on earth who dared to show himself, she, however, incurred no risk of want. (Hawthorne, 2004: 170)

(6) Plainly (G) detectable was the scar from her forehead (F). (China Daily, June 20, 2016)

In Example (5) and (6), "lonely" and "plainly" are two kinds of emotion, which are abstract ones, while "Hester's situation" and "the scar from her forehead" are discrete physical objects readily perceived as such in the normal course of human experience. Within Figure-Ground Theory, the figure is normally more salient than the ground. In cognitive view, one can easily find out the concrete thing but difficult to or cannot see the abstract one. Therefore, "lonely" and "plainly" refer to the grounds while "Hester's situation" and "the scar from her forehead" represent the figures, which attract the hearers' or readers' more attention.

Objectively speaking, "lonely" and "plainly" as the grounds, which are more abstract, can arouse the hearers' or readers' interest firstly, when 'Hester's situation" and "the scar from her forehead", as the figures, are more concrete ones eventually appear, the hearers or readers will pay more attention to them.

Therefore, through teachers' explanation of English inversions using the principle of specificity, students can bring human cognition, motivation and specific knowledge connected, and make a vivid understanding of English inversions.

\section{CONCLUSION}

Figure-Ground Theory model provides a new way of the teaching of English inversions. Teachers can use a more vivid way to explain English inversions and students can learn this grammar more easily by using this new approach. What's more, within the help of Figure-Ground Theory, students will not feel bored and difficult to learn this grammar. Therefore, Figure-Ground Theory plays a positive role in the teaching of English inversions.

\section{ACKNOWLEDGMENTS}

This work is supported by the Ministry of Education Research of Social Sciences Youth funded projects, China (Grant No. 17YJC740009).

\section{REFERENCES}

[1] K.d. Zhang, 'Yinyu daozhuangju de yupian gongneng' [Textual Functions of English Inversions from a Pragmatic Perspective], Waiguoyu [Journal of Foreign Languages], 2001(5), pp. 18-24.

[2] E. Rubin, Visuell Wahrgenommene Figure, Gyldendalske, 1921.

[3] F. Ungerer, H.J. Schmid, An Introduction to Cognitive Linguistics, Foreign Language Teaching and Research Press, 2001.

[4] J. Baldwin, Selected Western Legends and Stories, China Foreign Translation and Publishing Company, 1984.

[5] R.W. Langacker, Foundations of Cognitive Grammar. Vol. I: Theoretical Prerequisites, Peking University Press, 2004.

[6] N. Hawthorne, The Scarlet Letter. Trans. Zheng Shisheng. Wang Ruoping et al, Aviation Industry Press, 2004. 